\title{
A ESTRUTURA DA REDE SOCIAL DA MÃE/ACOMPANHANTE DA CRIANÇA HOSPITALIZADA*
}

\author{
Rita de Cássia Melão de Morais ${ }^{1}$, Tania Vignuda de Souza ${ }^{2}$, Isabel Cristina dos Santos Oliveira ${ }^{2}$, Juliana \\ Rezende Montenegro Medeiros de Moraes $^{2}$
}

\begin{abstract}
RESUMO: Objetivo: Analisar a estrutura da rede social da mãe/acompanhante durante a hospitalização da criança. Método: pesquisa qualitativa, em hospital pediátrico do Rio de Janeiro. Foram entrevistadas dez mães/ acompanhantes de fevereiro a dezembro de 2015. Utilizou-se o referencial teórico-metodológico e a análise de rede social de Lia Sanicola. Resultados: as redes primárias configuraram-se de tamanho médio e laços fortes, principalmente as redes das crianças que estão na primeira hospitalização, pois se mostraram mais numerosas comparadas com aquelas que já tiveram outras hospitalizações. Das redes secundárias, foram mencionadas: redes formal, terceiro setor e mercado. Não foram citadas as redes mista e informal. Conclusão: hospitalizações prolongadas e frequentes da criança interferem na dinâmica da rede social, tendo em vista que, ao longo das hospitalizações, ela se torna menor, porém com laços mais fortalecidos. A rede de atenção primária não foi mencionada e é justificada através do diagnóstico de doença crônica desde o nascimento.
\end{abstract}

DESCRITORES: Apoio social; Rede social; Família; Criança hospitalizada; Enfermagem pediátrica.

\section{STRUCTURE OF THE SOCIAL NETWORK OF MOTHERS/CAREGIVERS OF HOSPITALIZED CHILDREN}

ABSTRACT: Objective: Analyze the structure of the social network of mothers/caregivers during the hospitalization of their child. Method: Qualitative study in a pediatric hospital in Rio de Janeiro. Ten mothers/caregivers were interviewed from February to December 2015. A theoretical-methodological framework and social network analysis by Lia Sanicola were used. Results: The primary networks were medium-sized, with strong bonds, particularly the networks for children being hospitalized for the first time. They were more numerous than those for children who had been previously hospitalized. The following secondary networks were mentioned: formal, third sector and market. No mixed and informal networks were mentioned. Conclusion: Extended and frequent hospital stays of children affect the dynamics of social networks. Over the course of hospital stays, they become smaller, but the bonds within them are strengthened. The primary healthcare network was not mentioned, due to the fact that the children had been diagnosed with chronic diseases since birth.

DESCRIPTORS: Social support; Social networking; Family; Hospitalized child; Pediatric nursing.

\section{ESTRUCTURA DE LA RED SOCIAL DE LA MADRE/ACOMPAÑANTE DEL NIÑO HOSPITALIZADO}

RESUMEN: Objetivo: Analizar la estructura de la red social de la madre/acompañante durante la hospitalización del niño. Método: Investigación cualitativa, en hospital pediátrico de Rio de Janeiro. Fueron entrevistadas diez madres/acompañantes, entre febrero y diciembre de 2015. Se utilizó referencial teórico-metodológico y análisis de red social de Lia Sanicola. Resultados: Las redes primarias expresaron dimensión mediana y lazos fuertes, particularmente las redes de niños en su primera hospitalización, mostrándose más numerosas comparadas con las de niños previamente hospitalizados. De las redes secundarias, fueron mencionadas: red formal, tercer sector y mercado. No fueron citadas la red mixta y la informal. Conclusión: Las hospitalizaciones prolongadas y frecuentes del niño interfieren en la dinámica de la red social, considerando que, a lo largo de las hospitalizaciones, se hace menor, aunque con lazos más fortalecidos. La red de atención primaria no fue mencionada, justificándose por el diagnóstico de enfermedad crónica desde el nacimiento.

DESCRIPTORES: Apoyo Social; Red Social; Familia; Niño Hospitalizado; Enfermería Pediátrica.

*Artigo extraído da tese intitulada: "O familiar/acompanhante tecendo redes sociais durante a hospitalização da criança". Universidade Federal do Rio de Janeiro, 2016.

${ }^{1}$ Enfermeira. Doutora em Enfermagem. Docente de Enfermagem da Fundação Universidade Federal de Rondônia. Porto Velho, RO, Brasil.

${ }^{2}$ Enfermeira. Doutora em Enfermagem. Docente de Enfermagem da Universidade Federal do Rio de Janeiro. Rio de Janeiro, RJ, Brasil.

Autor Correspondente:

Rita de Cássia Melão de Morais

Universidade Federal do Rio de Janeiro

R. Afonso Cavalcanti, 275 - 20211-110 - Rio de Janeiro, RJ, Brasil

E-mail: ritamelao@gmail.com
Recebido: 02/02/2017

Finalizado: $16 / 11 / 2017$ 


\section{- INTRODUÇÃO}

A abordagem de rede social surgiu na área das ciências humanas e tem sido cada vez mais utilizada no campo da saúde. A utilização da rede social, como meio de investigação sobre as condições de saúde da população, dá-se a partir do entendimento que a saúde resulta de complexas relações entre fatores biológicos, psicológicos e sociais ${ }^{(1)}$.

As redes sociais constituem significativo recurso no cuidado à saúde e podem ser concebidas como o conjunto de relações interpessoais entre familiares, amigos, instituições, entre outros. Deste modo, o individuo que mantém sua identidade social recebe apoio, além de ter a possibilidade de desenvolver outras relações sociais. Estas redes sociais favorecem o entendimento de como seus membros adéquam suas tomadas de ações diante de suas necessidades específicas ${ }^{(2)}$.

A presença da mãe/acompanhante durante a hospitalização da criança tem respaldo legal através do Estatuto da Criança e do Adolescente (ECA), uma vez que, no Brasil, a garantia do direito de inserção de um responsável legal para o acompanhamento da criança ou do adolescente hospitalizado foi constituído pela Lei 8.069/90(3).

A partir da promulgação do ECA, que assegura esse direito da criança, verifica-se a presença do acompanhante, que na maioria dos casos é a mãe ${ }^{(4)}$. Quando a mãe tem um filho hospitalizado e necessita tornar-se acompanhante, ocorre o distanciamento de suas atribuições como mulher, trabalhadora e mãe de outros filhos para se dedicar exclusivamente à criança hospitalizada ${ }^{(5)}$.

O sofrimento causado pela doença e hospitalização da criança desequilibra temporariamente os membros da família e as atividades domésticas que anteriormente eram desenvolvidas exclusivamente pela mãe, pois passam a ser desempenhadas por outros familiares para que essa mãe possa permanecer no hospital. Neste sentido, não se pode pensar em hospitalização da criança desvinculada da família, pois esta se mobiliza para manter seu funcionamento e cria uma nova estrutura, para adaptar-se à realidade na qual se apresenta, e quando preciso, reestrutura-se para seguir adiante ${ }^{(6)}$.

Com base nesta situação de crise temporária, a mãe que permanece no hospital aciona redes sociais de forma a suprir suas necessidades ${ }^{(7)}$. A estrutura da rede social é dada pelo conjunto de laços perceptíveis que se estabelecem entre pessoas e redes. Esses laços, quando acionados, geram conexões que dão forma às redes. A abordagem de rede social, na verdade, é uma chave de acesso a uma realidade de relações humanas. As redes sofrem mudanças em sua estrutura no decorrer do tempo e dos acontecimentos, elas se movem em consequência da ocorrência de eventos $\operatorname{críticos}^{(2)}$.

Durante a hospitalização da criança, a rede social é composta tanto pela família e amigos, quanto pelas pessoas com as quais a mãe/acompanhante convive durante a hospitalização da criança, assim como as mães de outras crianças internadas e profissionais de saúde. Os profissionais da enfermagem, portanto, fazem parte da rede construída no ambiente hospitalar e podem contribuir de forma positiva para a vivência deste momento tão difícil na vida da criança e sua mãe/acompanhante, ao buscarem possibilidades de ajudá-los e/ou possibilitar que utilizem uma rede própria de apoio social ${ }^{(5,8)}$.

A construção de uma rede social que provê o apoio social durante a hospitalização da criança assegura à mãe/acompanhante o atendimento de algumas necessidades dentro e fora do cenário hospitalar, consequentemente garantindo sua permanência com a criança no hospital. Entre as necessidades intra-hospitalares, destacam-se o apoio emocional, material (roupas limpas, produtos de higiene, alimentos) e financeiro. No cenário extra-hospitalar, destacam-se, principalmente, os cuidados com os outros filhos e as atividades domésticas ${ }^{(7)}$.

Na literatura científica nacional e internacional, foram encontrados seis artigos que abordavam a rede social dos familiares de crianças hospitalizadas. Estes seis estudos apontaram para a importância da rede de apoio de solidariedade entre mães acompanhantes que são construídas no cenário hospitalar, principalmente pela ausência de apoio familiar ${ }^{(5)}$.

Três estudos identificaram que a estrutura das redes de apoio são compostas, principalmente, pela rede familiar e pelos profissionais do serviço de saúde ${ }^{(8-10)}$. No entanto, as fragilidades encontradas estão relacionadas a não continuidade do apoio recebido durante a internação e a falta de envolvimento do 
profissional de saúde ${ }^{(11)}$. Quanto à rede secundária, o estudo aponta basicamente as instituições de saúde de nível terciário ${ }^{(12)}$.

A rede social que as mães/acompanhantes de criança hospitalizada estabelecem em seu entorno e os serviços que a acolhem constituem-se em um caminho possível para o entendimento e atuação profissional voltada para a complexidade das relações sociais envolvidas na hospitalização da criança ${ }^{(13)}$.

Os estudos de redes sociais beneficiam as relações entre indivíduos e caracterizam a teia de relações sociais em torno dos mesmos, incluindo os contatos e a natureza dos laços que se ligam. O conhecimento da rede social da mãe/acompanhante da criança hospitalizada é importante, pois permite à equipe de saúde identificar quem são e como são os laços dos indivíduos que configuram essas redes de apoio, além de identificar quais são suas funções e elementos deste universo relacional do acompanhante que podem ser acionados a fim de tornar o apoio mais efetivo ${ }^{(14)}$.

Apesar da constatação da importância das redes sociais da mãe/acompanhante para sua permanência com a criança no hospital, há uma carência da identificação da estrutura de tais redes e suas contribuições para o seu fortalecimento no momento de crise, que é a hospitalização da criança. Diante do exposto, o objetivo do estudo foi analisar a estrutura da rede social da mãe/acompanhante durante a hospitalização da criança.

\section{- MÉTODO}

Estudo de abordagem qualitativa descritiva fundamentada no referencial teórico metodológico de Rede Social de Lia Sanicola. Para a autora, as redes sociais podem ser divididas em duas grandes categorias: Rede Primária e Rede Secundária, que se diferenciam pelos tipos de intercâmbios que ocorrem entre os indivíduos ${ }^{(2)}$.

As Redes Primárias são constituídas por laços de família, parentesco, amizade e vizinhança, já as Redes Secundárias se dividem em formal, informal, de terceiro setor, de mercado, ou mista, distinguindose entre si pelo tipo de troca intercambiada. A Rede Secundária formal é constituída pelo conjunto de instituições estatais que formam o sistema de bem-estar social da população. A Rede Secundária informal é um desenvolvimento da rede primária, constituída por grupos informais de ajuda mútua. As Redes Secundárias do terceiro setor são aquelas constituídas por organizações da sociedade civil que prestam serviços, mas sem fins lucrativos. As Redes Secundárias de mercado dizem respeito a atividades econômicas rentáveis, sendo sua existência ligada ao dinheiro e aos lucros. Por fim, as Redes Secundárias mistas são aquelas que mesclam os tipos de intercâmbios, ou seja, ao mesmo tempo em que prestam serviço garantindo um direito, o faz mediante pagamento ${ }^{(2)}$.

O cenário do estudo foi a Unidade de Internação Pediátrica de um Hospital público especializado em pediatria, referência para diagnósticos clínicos e cirúrgicos, situado na cidade do Rio de Janeiro e que interna crianças na faixa etária de 1 mês a 12 anos. As crianças são provenientes do estado do Rio de Janeiro ou de outros estados do Brasil.

Neste contexto, os participantes foram 10 mães, que acompanhavam a criança hospitalizada e aceitaram participar do estudo voluntariamente. Os critérios de inclusão dos participantes neste estudo foram: acompanhantes que permaneciam por período integral com a criança, que estivessem por pelo menos uma semana no hospital e não apresentassem dificuldade/limitação para se comunicar. Os critérios de exclusão foram: acompanhantes eventuais da criança; menores de 18 anos; acompanhantes de crianças em estado clínico crítico/instável no momento da coleta.

A coleta de dados ocorreu no período de fevereiro a dezembro de 2015. Para selecionar os participantes, a enfermeira do plantão era consultada para informar quais acompanhantes permaneciam com a criança integralmente durante a semana e, a partir desta informação, foram então consultadas aleatoriamente sobre seu interesse em participar do estudo.

As entrevistas eram individuais, utilizando-se um formulário de caracterização dos participantes e um roteiro semiestruturado para construção do mapa de redes. Estas foram gravadas e transcritas a seguir pelo próprio pesquisador. Garantiu-se o anonimato dos participantes entrevistados, que foram identificados de acordo com o grau de parentesco com a criança hospitalizada, e os demais membros 
citados na rede foram identificados de acordo com o grau de parentesco ou sua relação social com o entrevistado. As entrevistas cessaram pela saturação teórica, pois não houve novos elementos das falas dos participantes.

A análise da rede de relacionamentos das mães/acompanhantes foi realizada através da elaboração do mapa da sua rede social que permitiu o conhecimento da dimensão e da forma como os laços se estabelecem entre os diversos tipos de rede presentes. Para analisar a rede social, foi necessário conhecer sua estrutura quanto a: amplitude - no que diz respeito à quantidade de pessoas presentes, pois a amplitude permite afirmar se uma rede é pequena (até nove), média (dez a trinta) ou grande (mais de trinta membros) e permite analisar os tipos de laços estabelecidos entre os membros $\operatorname{citados}^{(2)}$.

Para a confecção do mapa da rede social, foi imprescindível a utilização de símbolos sob a forma de figuras geométricas (representam os tipos de rede social) e de traçados gráficos (indicam os tipos de laços) ${ }^{(2)}$, conforme observa-se na Figura 1.

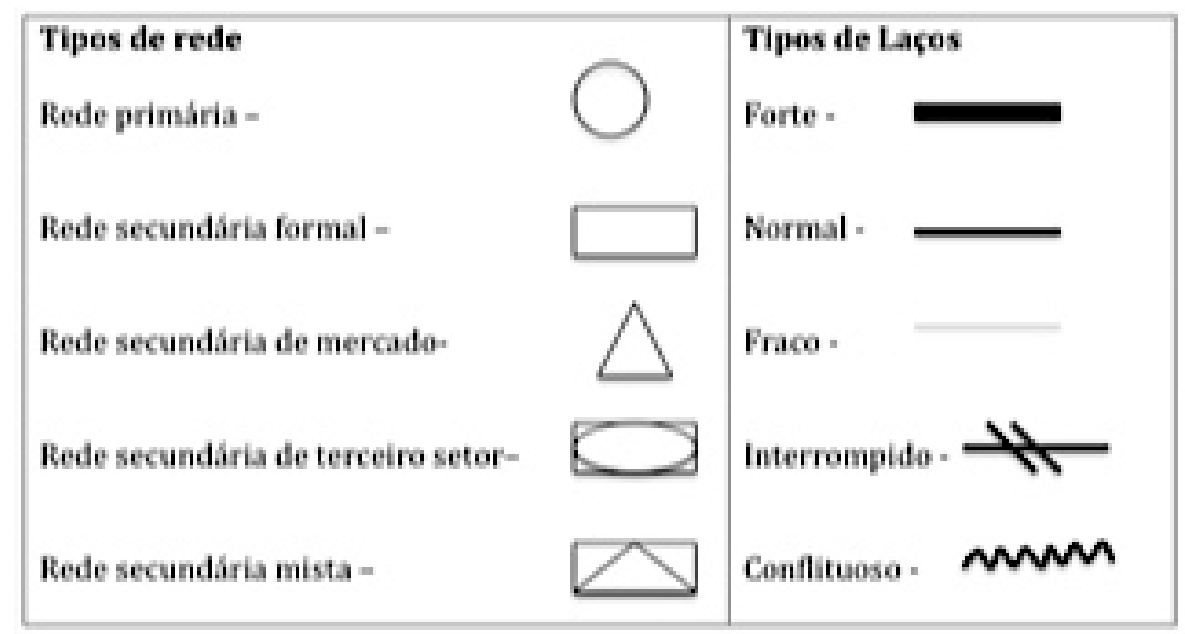

Figura 1 - Representação dos tipos de redes e laços. Rio de Janeiro, RJ, Brasil, 2016

Este estudo foi avaliado pelo Comitê de Ética e Pesquisa da instituição proponente e coparticipante e após aprovação recebeu o parecer n. 938.786/2015.

\section{RESULTADOS}

Os resultados foram obtidos através de alguns perfis entrevistados. Quanto à caracterização das dez entrevistadas, nove eram mães e uma era bisavó (responsável legal). A faixa etária variou de 18 a 58 anos. Quanto ao local de residência, cinco residiam na cidade do Rio de Janeiro, quatro residiam em outros municípios do Estado e uma era proveniente da África, mas no momento da coleta de dados residia temporariamente na cidade do Rio de Janeiro para o tratamento de saúde da criança.

No que diz respeito ao estado civil, oito viviam com o companheiro e duas eram casadas. O número de filhos variou de um a seis. Com relação ao nível de instrução: duas possuíam o Ensino Fundamental completo; três, o Ensino Fundamental incompleto; três, o Ensino Médio completo; uma, o ensino médio incompleto; e uma, o ensino superior completo.

No que se refere ao diagnóstico médico da criança, a maioria era acometida por enfermidades crônicas tais como: Síndrome de Arnold Chiari (2) (tipos 1 e 2); Investigação diagnóstica (2) (suspeita de fibrose cística); paralisia cerebral (1); encefalopatia crônica não progressiva (1); Síndrome de West (1); Histoplasmose Pulmonar Crônica (1); Meningoencefalite (1); e Atresia de vias biliares (1). Quanto ao tempo de hospitalização da criança, variou de sete dias a oito meses de internação.

É importante destacar que quatro das crianças estavam em sua primeira hospitalização e se 
encontravam em investigação diagnóstica (2), enquanto duas crianças nasceram e foram encaminhadas direto para o hospital - contexto de estudo - uma com Síndrome de Arnold Chiari tipo 1 e outra com Atresia de Vias Biliares. As outras seis crianças possuíam internações anteriores e sua frequência variou de duas a quatorze vezes.

O desenho do mapa da rede social, obtido durante as entrevistas, possibilitou uma visão do contexto relacional em que a mãe/acompanhante da criança hospitalizada está inserida. Neste sentido, a Figura 2 apresenta o mapa com a síntese da rede social das dez participantes, ilustrando as redes primárias e secundárias, com os principais membros citados e os respectivos laços estabelecidos no período de hospitalização.

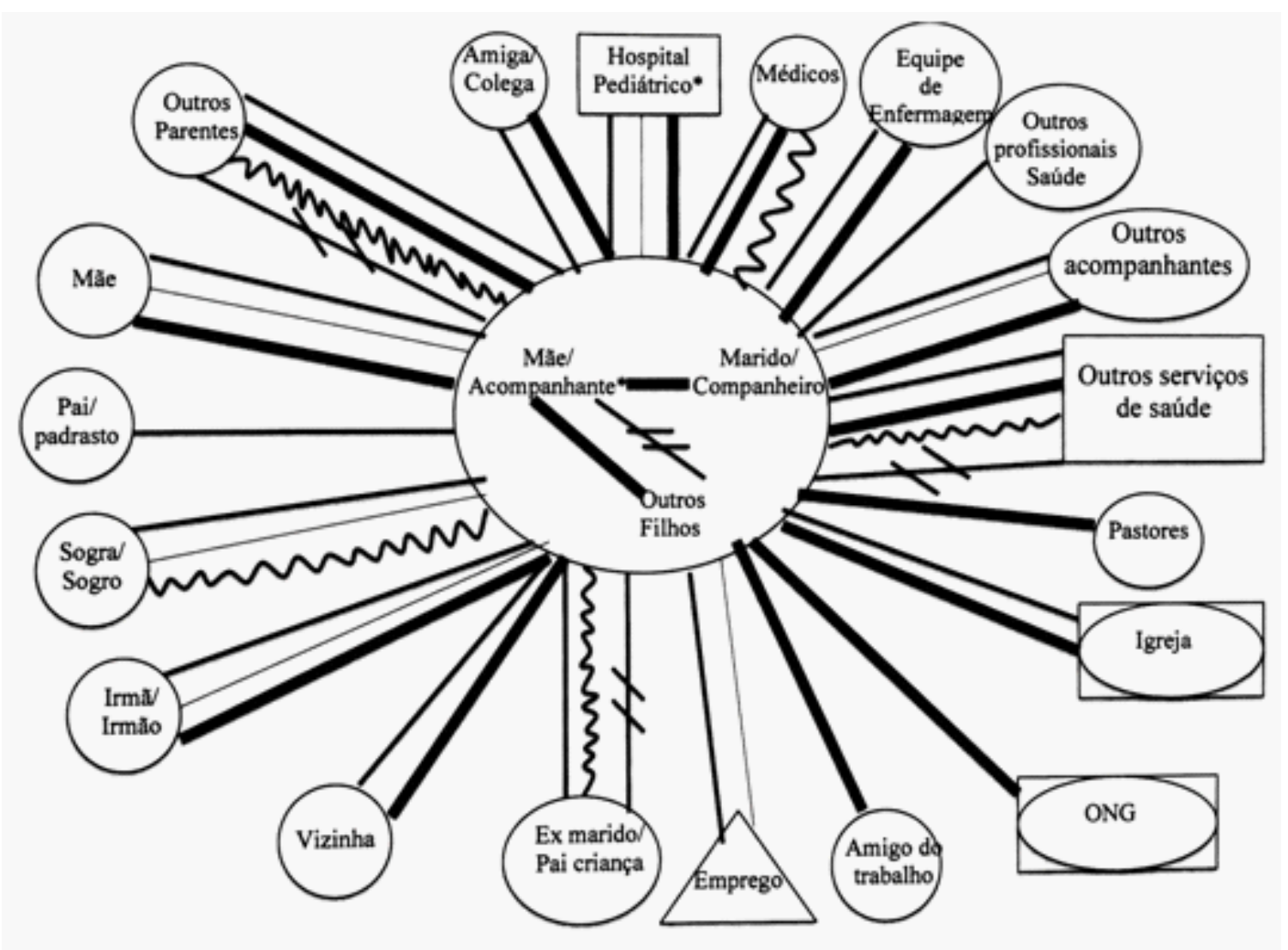

Figura 2 - Mapa com a síntese das dez redes configuradas. Rio de Janeiro, RJ, Brasil, 2016

Para compor o mapa com a síntese, foram consideradas todas as relações sociais construídas nos mapas individuais de cada mãe/acompanhante, tendo em vista que as redes primárias e secundárias foram compostas pelos membros da família com o mesmo grau de parentesco, bem como outras pessoas e instituições. No entanto, no que se refere aos laços estabelecidos, estes se mostraram: normal, forte, conflituoso e rompido, por isso, apresenta-se na figura mais de um traço.

Constata-se que, dos dez mapas de rede social, nove foram configurados como de amplitude média (10 a 30 membros), pois variaram de 15 a 25 membros. Apenas um mapa de rede social se configurou como grande (mais de 30 membros) por apresentar 32 membros, assim como estabelecido pelo referencial teórico metodológico adotado ${ }^{(2)}$.

Ressalta-se que as redes primárias das mães/acompanhantes das crianças que estão na sua primeira hospitalização, apesar de consideradas em uma amplitude média, possuíam um maior quantitativo de membros, se comparado às redes primárias das mães acompanhantes das crianças que reinternaram e que estavam por mais tempo hospitalizadas, ou seja, estas apresentavam uma rede primária mais restrita, porém com laços mais fortalecidos. Pode-se exemplificar a rede social configurada como grande, aquela que era a de primeira hospitalização. 
Ainda no que se refere à rede primária, as dez mães/acompanhantes entrevistadas estabeleceram laços fortes com seus companheiros/maridos e filhos e seis delas estabeleceram laço forte com a mãe (parente), sendo que uma possui laço normal e outra, conflituoso. Duas participantes não citaram suas mães, pois eram falecidas. Afirmaram possuir laços normais com outros membros da família que são denominados parentes como tias: sendo seis delas com laços fortes, seis tias com laço normal e uma tia com laço conflituoso. De oito primas citadas, metade possuía laço forte e a outra metade laço normal. Com relação aos sogros (sete sogras e dois sogros), seis possuíam laço normal, dois conflituosos e um frágil.

Por fim, foram citadas onze amigas, sendo seis com laço normal, cinco com laço forte e uma acompanhante foi considerada como amiga estabelecendo laço forte. Destaca-se que duas mães acompanhantes citaram vizinhas, uma com laço normal e uma com laço forte.

Diante do exposto, constata-se que no adoecimento e hospitalização da criança, todas as mães/ acompanhantes do estudo, independente do número de hospitalizações e tempo de internação da criança, mencionam poder contar predominantemente com os seguintes membros da sua rede primária: mãe, marido/companheiro e outros filhos, destacando-se o laço forte. Os outros membros citados na rede primária em que predominou o laço de normalidade foram: pai/padrasto, tias, sogros, primas e amigas, no entanto, constata-se que o tipo de laço construído na rede primária da mãe/ acompanhante varia conforme o atendimento das suas necessidades.

Da rede secundária, todas citaram as instituições de saúde (Rede Secundária Formal) envolvidas no tratamento e acompanhamento da criança, bem como igrejas, Organização Não Governamental (ONG) (rede secundária de terceiro setor), e emprego (rede secundária de mercado), sendo os membros da rede secundária: acompanhantes de outras crianças hospitalizadas e profissionais de saúde, pastores e, por fim, colegas de trabalho.

Da Rede Secundária formal, todas as entrevistadas mencionaram em especial o hospital, cenário do estudo, sendo que duas participantes referiram ter um laço forte, uma afirmou laço frágil e as demais laço normal. No entanto, sete participantes citaram outros hospitais, sendo que quatro foram classificados com um laço forte, locais onde foram feitos os diagnósticos e encaminhamento para o local do estudo. Destaca-se que estes locais foram os de nascimento da criança e hospitais que a criança permaneceu por mais de três meses fazendo tratamento clínico. Dois hospitais, localizados fora do Município do Rio de Janeiro, foram citados com laço interrompido, porque no local não havia disponibilidade de médicos.

Destaca-se, nas instituições de saúde citadas, a importância das seguintes categorias profissionais: equipe de enfermagem, médicos, terapeuta ocupacional, fisioterapeuta, psicóloga, assistentes sociais e técnico administrativo, bem como outras mães acompanhantes.

Entre os membros da equipe de enfermagem foram citados oito enfermeiros e 11 técnicos de enfermagem, no entanto, ao se referirem sobre o estabelecimento dos laços, citaram laço forte apenas com um enfermeiro, enquanto que todos os outros da equipe de enfermagem foram referidos com laços normais. Contudo, estes foram indicados como pessoas atenciosas, carinhosas e disponíveis para atender.

Quinze médicos foram mencionados, sendo oito com laço normal, seis com laço forte e uma com laço conflituoso. Os demais profissionais da equipe de saúde, que ao todo foram cinco - terapeuta ocupacional, fisioterapeuta, psicóloga e duas assistentes sociais - apresentaram laço normal. Acrescentase ainda um profissional com o cargo de técnico administrativo que estabeleceu laço normal. Ainda foram citadas 13 mães de outras crianças hospitalizadas, destas, nove mantinham um laço normal, três, um laço forte e uma, frágil.

No que se refere à rede secundária de terceiro setor, quatro mães citaram a igreja, sendo três com laço forte e uma com laço normal. Ressalta-se que a participante estrangeira citou uma ONG, à qual referiu laço forte. Quanto aos membros da igreja, uma mãe/acompanhante referiu ter laço forte com dois pastores que são considerados como amigos e ainda foram citadas quatro amigas que são irmãs de igreja com laço normal.

Quanto à rede secundária de mercado, três mães/acompanhantes destacaram o local de trabalho 
do seu esposo, cujo vínculo é normal e duas citaram o seu local de trabalho como frágil, justificado pela incerteza de retorno ao final da licença maternidade. No entanto, estas duas mães afirmaram estabelecer laços fortes com os colegas de trabalho.

Constata-se que as mães/acompanhantes estabelecem uma rede social secundária diversificada, no entanto, nenhuma participante citou a rede secundária mista e informal. Destaca-se ainda que a rede de atenção primária e secundária de saúde não foi citada pelas participantes, ou seja, a rede de atenção terciária de saúde continua sendo a mais procurada, justificando-se pela busca das especialidades, tecnologias e resoluções de problemas considerados crônicos, conforme o diagnóstico das crianças. A maioria citou o hospital, cenário do estudo, com laço normal; e outras instituições de saúde, com laço forte, principalmente as instituições de saúde (local de nascimento) que fizeram o diagnóstico clínico inicial.

Portanto, ao relacionarem os laços com os profissionais de saúde, é relevante observar que referiram ser mais forte com os profissionais que demonstravam maior afeto e atenção para com a criança e ela. Poucas mães citaram o trabalho como sua rede social, tendo em vista que a maioria delas não possuía vínculo empregatício.

\section{DISCUSSÃO}

A amplitude média da maioria das redes identificadas corrobora com o encontrado em estudo realizado com famílias de criança hospitalizada em que a maioria dos mapas eram de amplitude média ${ }^{(15)}$, ou seja, constituída de 10 a 30 membros $^{(2)}$. Em um evento estressor, como a hospitalização da criança, a existência de uma rede social com diversos membros pode ser mais segura do que uma relação única, além disso, os membros podem oferecer diferentes tipos de apoio, auxiliando na diminuição do estresse de situações difíceis ${ }^{(8)}$.

Cabe destacar que ninguém estabelece relação com uma única pessoa, inclusive o que determinará segurança ou não à mãe/acompanhante poderá estar relacionado não com o número de pessoas que fazem parte da sua rede social, e sim com os tipos de laços estabelecidos, e quais necessidades são atendidas.

Geralmente, a rede social dos familiares acompanhantes durante a hospitalização da criança é composta pelas pessoas mais significativas, entre elas: o companheiro/marido, seguido da mãe, justificado por ser a pessoa com quem os acompanhantes da criança podem contar ${ }^{(15-16)}$. As redes sociais primárias dos acompanhantes de crianças hospitalizadas são compostas pelas relações familiares e de amizade, através das quais recebem apoio emocional, ajuda material e de $\operatorname{serviços}^{(14,17)}$.

A família constitui a primeira experiência relacional da pessoa, sendo o primeiro e mais importante nó das redes, porque é constante ao longo do tempo, desde o nascimento até a morte. A família continua sendo um ponto de referência que sempre reaparece para o bem e para o mal, reapresentando-se como recurso ou como obstáculo ${ }^{(2)}$.

Somado aos membros familiares, nas redes primárias, são incluídos os amigos. A competência do amigo consiste na proximidade afetiva (emocional), que se mantém com a distância física, capaz de compartilhar das alegrias e tristezas do outro, de saber manter um segredo com lealdade, de saber distanciar-se e de saber aproximar-se para dar um conselho adequado ${ }^{(2)}$. Neste sentido, entende-se quando a mãe/acompanhante estabelece laços fortes com outras acompanhantes por compartilharem do mesmo sentimento e preocupação com a criança internada.

O apoio de amigos e vizinhos faz-se presente, além do apoio da família, no sentido de auxiliá-la a se organizar, assim como assumem tarefas domésticas e o cuidado dos outros filhos ${ }^{(15,18)}$. A rede de vizinhança pode ser ativada ou não. Ressalta-se que muitas vezes o vizinho é um importante recurso, interpretado e mobilizado em diferentes circunstâncias ${ }^{(2)}$.

As redes secundárias são caracterizadas principalmente por relações não escolhidas, pelo fato de serem institucionais ${ }^{(2)}$. No caso dos profissionais de saúde, estes se ligam às mães/acompanhantes por situações e contextos relacionados ao tratamento e assistência à saúde da criança ${ }^{(15,19-20)}$. Destaca-se 
que a equipe de enfermagem são os profissionais que apresentam maior contato com a criança e seus acompanhantes, seguido da equipe médica ${ }^{(15)}$.

As instituições de saúde constituem o sistema de bem estar social no qual ocorre troca de direitos e essa troca deve ser complementar à rede primária, auxiliando-a a desenvolver sua autonomia, mas não deve ser a principal fonte de apoio da rede social ${ }^{(2)}$. Dentro do hospital são formadas muitas redes de apoio, à medida que os integrantes das famílias passam a compartilhar um mesmo ambiente, além de experiências e sofrimentos relacionados ao processo saúde-doença, de modo a conseguirem, juntos, resgatar a sua dignidade humana ${ }^{(5)}$.

As redes secundárias do terceiro setor são aquelas que se constituem como organizações sem fins lucrativos onde ocorre a troca de solidariedade, a constituição de direito e apresentam-se como suplentes do estado, como é o caso das igrejas ${ }^{(2)}$. Estas redes são consideradas fundamentais, pois garantem às mães/acompanhantes suprir algumas das necessidades materiais, como cesta básica e roupas, bem como apoio emocional, trazendo palavras de conforto espiritual, motivações, incentivos, fé, esperança, entre outros ${ }^{(7,21)}$.

As congregações religiosas, mais especificamente as evangélicas, têm se tornado fonte de apoio e resolução de problemas, caracterizando-se pela união com pessoas como pastores e irmãos de igreja, pois compartilham a mesma fé, vinculando-se por meio desta e podendo se tornar uma amizade. A relação com um companheiro religioso é percebida como uma fonte de estímulo por meio do apoio emocional baseado nas crenças religiosas, como guia cognitivo e de conselhos ${ }^{(14-15)}$.

A rede secundária de mercado é uma organização que pertence à esfera econômica, como a atividade profissional. Vale destacar que esse tipo de rede não cria vínculos, a não ser em relação ao que se troca. Ainda, a autora afirma que o colega de trabalho é outro tipo de vizinhança que, por sua vez, é diferente da relação com o amigo, na qual há uma experiência de escolha, de afeição profunda ${ }^{(2)}$.

Este estudo apresenta como limitação a escolha do cenário do estudo que hospitaliza principalmente crianças portadoras de doenças crônicas, impossibilitando o conhecimento das redes sociais de crianças que se hospitalizam por causas agudas ou tratamentos de curta duração, não sendo possível neste caso generalizar.

\section{CONCLUSÃO}

O estudo mostra que a construção das redes sociais das mães/acompanhantes apresentou-se de forma diversificada, e que a rede primária, representada pela família nuclear (marido/companheiro e filhos) e a mãe, mostrou-se com laços mais fortes. A situação de hospitalizações prolongadas e frequentes da criança interfere na dinâmica dessa rede social, tendo em vista que, ao longo das hospitalizações, os membros que compõem a rede primária diminuíram, porém, com laços mais fortalecidos.

A rede secundária foi constituída principalmente pelas instituições de nível terciário de saúde, igreja e emprego. Entre os membros dessa rede secundária, foram considerados, principalmente, a equipe de enfermagem e médica, bem como pastores e colegas de trabalho.

Conclui-se que a rede de atenção primária e secundária de saúde não são consideradas pelas participantes do estudo, pois as crianças não foram atendidas em nenhumas das fases de acompanhamento de saúde nesses locais. Portanto, é importante que estas instituições hospitalares e seus profissionais de saúde possam fazer articulações com as redes de atenção primária e secundária de saúde de forma a acompanhar a criança no momento da alta.

\section{REFERÊNCIAS}

1. Souza MHN, Souza IEO, Tocantins FR. The use of social network methodological framework in nursing care to breast feeding women. Rev. Latino-Am Enfermagem. [Internet] 2009;17(3) [acesso em 11 jul 2016]. Disponível: http://dx.doi.org/10.1590/S0104-11692009000300012. 
2. Sanicola L. As Dinâmicas de Rede e o Trabalho Social. 2a ed. ampliada. São Paulo: Veras Editora; 2015.

3. Brasil. Lei n. 8.069, de 13 de junho de 1990. Dispõe sobre o Estatuto da Criança e do Adolescente, e dá outras providências. Diário Oficial da União, Brasília, 14 jun, 1990. Seção 1, p. 13563.

4. de Albuquerque DB, de Morais RCM, de Macedo IF, Vieira RFC, de Souza TV. A família no cenário hospitalar pediátrico a partir da década de 1990: uma revisão integrativa. Cogitare Enferm. [Internet] 2013;18(4) [acesso em 15 jun 2016]. Disponível: http://dx.doi.org/10.5380/ce.v18i4.34938.

5. Molina RCM, Higarashi IH, Marcon SS. Importance attributed to the social support network by mothers with children in an intensive care unit. Esc. Anna Nery. [Internet] 2014;18(1) [acesso em 09 jul 2016]. Disponível: http:// dx.doi.org/10.5935/1414-8145.20140009.

6. Gomes GC, de Oliveira PK. Family Experience in the hospital during child hospitalization. Rev. Gaúcha Enferm. [Internet] 2012;33(4) [acesso em 09 jul 2016]. Disponível: http://dx.doi.org/10.1590/S1983-14472012000400021.

7. de Morais RCM, de Souza TV, Oliveira ICS. The (dis)satisfaction of the companions about their condition of staying in the pediatric ward. Esc. Anna Nery. [Internet] 2015;19(3) [acesso em 11 jul 2016]. Disponível: http:// dx.doi.org/10.5935/1414-8145.20150053.

8. Polita NB, Tacla MTGM. Network and social support to families of children with cerebral palsy. Esc. Anna Nery. [Internet] 2014;18(1) [acesso em 07 mai 2017]. Disponível: http://dx.doi.org/10.5935/1414-8145.20140011.

9. Hayakawa LY, Marcon SS, Higarashi IH, Waidman MAP. Support network to the families of children admitted in a pediatric intensive care unit. Rev. bras. enferm. [Internet] 2010;63(3) [acesso em 10 mar 2017]. Disponível: http:// dx.doi.org/10.1590/S0034-71672010000300015.

10. Di Primio AO, Schwartz E, Bielemann VLM, Burille A, Zillmer JGV, Feijó AM. Social network and support bonds of the families of children with cancer. Texto Contexto Enferm. [Internet] 2010;19(2) [acesso em 07 ago 2017]. Disponível: http://dx.doi.org/10.1590/S0104-07072010000200015.

11. Araújo YB, Reichert APS, de Vasconcelos MGL, Collet N. Fragility of the social network of families of children with chronic disease. Rev. bras. enferm. [Internet] 2013;66(5) [acesso em 07 ago 2017]. Disponível: http://dx.doi. org/10.1590/S0034-71672013000500006.

12. da Nóbrega VM, Collet N, da Silva KL, Coutinho SED. Rede e apoio social das famílias de crianças em condição crônica. Rev. Eletr. Enf. [Internet] 2010;12(3) [acesso em 01 jul 2017]. Disponível: http://dx.doi.org/10.5216/ree. v12i3.7566.

13. Vieira LB, Souza IEO, Tocantins FR, Pina-Roche F. Support to women who denounce experiences of violence based on her social network. Rev Latino-Am. Enfermagem. [Internet] 2015;23(5) [acesso em 11 jul 2016]. Disponível: http://dx.doi.org/10.1590/0104-1169.0457.2625.

14. Menezes M, Moré CLOO, Barros L. Redes Sociais significativas de familiares acompanhantes de crianças hospitalizadas. Atas-investigação qualitativa na saúde. [Internet] 2015;(1) [acesso em 12 jul 2016]. Disponível: http://proceedings.ciaiq.org/index.php/ciaiq2015/article/view/126/122.

15. Menezes M, Moré CLOO, Barros L. Social Networking Family of Caregivers during Hospitalization of Children. Rev. esc. enferm. USP. [Internet] 2016;50(n.esp) [acesso em 09 Jul 2016]. Disponível: http://dx.doi.org/10.1590/ S0080-623420160000300016.

16. da Costa RF, Zeitoune RCG, Queiroz MVO, García CIG, García MJR. Adolescent support networks in a health care context: the interface between health, family and education. Rev. esc. enferm. USP. [Internet] 2015;49(5) [acesso em 07 ago 2017]. Disponível: http://dx.doi.org/10.1590/S0080-623420150000500005.

17. Pennafort VPS, Queiroz MVO, Nascimento LC, Guedes MVC. Network and social support in family care of children with diabetes. Rev. bras. enferm. [Internet] 2016;69(5) [acesso em 04 ago 2017]. Disponível: http://dx.doi. org/10.1590/0034-7167-2015-0085.

18. dos Santos LM, Valois HR, Santos SSBS, Carvalho ESS, de Santana RCB, Sampaio SS. Applicability of theoretical model to families of children with chronic disease in intensive care. Rev. bras. enferm. [Internet] 2014;67(2) [acesso em 09 jul 2016]. Disponível: http://dx.doi.org/10.5935/0034-7167.20140024. 
19. Gomes GC, Erdmann AL, de Oliveira PK, Xavier DM, Santos SSC, Farias DHR. The family living the time during the hospitalization of the child: contributions for nursing. Esc. Anna Nery. [Internet] 2014;18(2) [acesso em 09 jul 2016]. Disponível: http://dx.doi.org/10.5935/1414-8145.20140034.

20. Barbosa TA, Reis KMN, Lomba GO, Alves GV, Braga PP. Rede de apoio e apoio social às crianças com necessidades especiais de saúde. Rev. Rene. [Internet] 2016;17(1) [acesso em 06 ago 2017]. Disponível: http:// dx.doi.org/10.15253/2175-6783.2016000100009.

21. Souza IP, Bellato R, de Araújo LFS, de Almeida KBB. Genogram and eco-map as tools for understanding family care in chronic illness of the young. Texto Contexto Enferm. [Internet] 2016;25(4) [acesso em 07 ago 2017]. Disponível: http://dx.doi.org/10.1590/0104-07072016001530015. 